\title{
Design of an active seed throwing and cleaning unit for pneumatic rice seed metering device
}

\author{
He Xing ${ }^{1,2}$, Zaiman Wang ${ }^{1,2}$, Xiwen Luo ${ }^{1,2}$, Ying Zang ${ }^{1,2^{*}}$, Wenwu Yang ${ }^{1,2}$, \\ Minghua Zhang ${ }^{1,2}$, Yuexin Ma ${ }^{1,2}$ \\ (1. Key Laboratory of Key Technology on Agricultural Machine and Equipment, Ministry of Education, South China Agricultural University, \\ Guangzhou 510642, China; 2. College of Engineering, South China Agricultural University, Guangzhou 510642, China)
}

\begin{abstract}
To address the clogging of the rice seed metering device after a long period of operation without affecting the precision of normal seeding, an active seed throwing and cleaning unit was designed based on the fact that magnets of the same pole were mutually exclusive. The working principle of the two devices was analysed theoretically, and a mechanical model was created according to the relationship between the repulsion forces of magnets and the spring forces of springs. The super hybrid rice Y-2 You 900 with $22.5 \%$ moisture content (wet basis) was used as the test object. The whole factor experiments were carried out under different negative pressures, rotational speeds of the suction plates, and lengths of probes. The results indicated that under any test conditions, the active seed throwing and cleaning unit worked normally. The results of high-speed photography showed that the rate of seed cleaning was $100 \%$. The results also showed that the optimal negative pressure was $0.8 \mathrm{kPa}$. The probability of $1-3$ seeds per hill for the seed metering device was approximately $95 \%$ under the optimal negative pressure. The optimal length of the probe was found to be $2 \mathrm{~mm}$. The average qualified rate of hill space was $96.04 \%$ under the optimal length of probe, the longer the length of the probe, the lower the qualified rate of hill space. It also showed that an active seed throwing and cleaning unit could effectively avoid the hole clogging caused by the long-term operation and had no influence on the normal operation of the pneumatic rice seed metering device. The active seed throwing and cleaning unit improved the stability of the seed metering device, and the research provided a reference for the optimal design of seed throwing and cleaning structures of the pneumatic rice seed metering device.

Keywords: agricultural machinery, seed metering device, seed cleaning, anti-clogging, pneumatic seed metering, precision seeder DOI: $10.25165 /$ j.ijabe. 20181102.3844
\end{abstract}

Citation: Xing H, Wang Z M, Luo X W, Zang Y, Yang W W, Zhang M H, et al. Design of an active seed throwing and cleaning unit for pneumatic rice seed metering device. Int J Agric \& Biol Eng, 2018; 11(2): 62-69.

\section{Introduction}

Rice is the main economic and food crop in the world. Mechanized planting of rice is mainly divided into two types: mechanical transplanting and mechanical direct seeding. Compared to mechanical transplanting, mechanical direct seeding can avoid the process of raising rice seedlings, reduce the input of prophase cost, and does not affect yield. It is expected to be the developing trend in mechanized rice planting in the future ${ }^{[1-3]}$. With further development of agronomic techniques, the quality of rice seeds can be also improved. Compared to conventional rice and common hybrid rice, the super hybrid rice has higher tillering

Received date: 2017-10-09 Accepted date: 2018-02-27

Biographies: He Xing, $\mathrm{PhD}$ candidate, research interests: agricultural mechanization and automation, Email: 675974347@qq.com; Zaiman Wang, Engineer, research interests: agricultural mechanization and automation, Email: wangzaiman@scau.edu.cn; Xiwen Luo, Professor, research interests: agricultural mechanization and automation, Email: xwluo@scau.edu.cn; Wenwu Yang, PhD candidate, research interests: agricultural mechanization and automation, Email: yangwenwu@scau.edu.cn; Minghua Zhang, PhD, research interests: agricultural mechanization and automation, Email: zhangminghuascau (a)163.com; Yuexin Ma, Graduate student, research interests: agricultural electrification and automation, Email: 1309264642@qq.com.

*Corresponding author: Ying Zang, $\mathrm{PhD}$, Professor, research interests: agricultural mechanization and automation. South China Agricultural University, Key Laboratory of Key Technology on Agricultural Machine and Equipment, Ministry of Education, Guangzhou 510642, China. Email: yingzang@ scau.edu.cn. ability and higher yield ${ }^{[4]}$. When direct seeding is adopted, only 1-3 seeds are needed at each hill to meet the requirements of rice growth $^{[5]}$.

The pneumatic rice precision direct seeding technique is a combination of machinery and air flow. This technique has the advantages of high seeding precision, low seed damage rate, and strong adaptability and can satisfy the seeding demands of many kinds of seeds. However, existing pneumatic seed metering devices are mainly for soybean, corn, wheat, rape and other crops. Seed metering devices have been widely used in actual production, and theoretical research is also relatively mature ${ }^{[5]}$. Yasir ${ }^{[6]}$ studied the pneumatic metering device for wheat, analysed the whole movement process of the seed metering device by theoretical means and experiment, and obtained the relation and mutual influence of each parameter. Singh et al. ${ }^{[7]}$ studied the shape and size of air holes in a pneumatic seed metering device. The optimum structure parameters were obtained from theory and rape experiments. Karayel et al..$^{[8-10]}$ and Ozmerzi et al. ${ }^{[11]}$ carried out a series of studies on the application of pneumatic metering devices to different crops. The equation of the relationship between vacuum and seed characteristics was established, and the structure parameters of a seed metering device were optimized. This kind of seed metering device has been widely used. Yazgi et al. ${ }^{[12,13]}$ studied the uniformity of a pneumatic seed metering device. The RSM method was used to analyse the vacuum of a pneumatic seed metering device, the diameter of the suction hole and the rotation speed of the sucking plate. It provided a reference for the 
uniformity of seeding.

The existing pneumatic rice seed metering device uses a combination of positive pressure and negative pressure to carry out seeding, and the seeding precision (namely, the probabilities of 1-3 seeds per hill) is approximately $95 \%$, and the probability of an empty hill is less than $3 \%$. This meets the requirements of field sowing. However, compared to other smooth seeds, rice seeds contain many impurities, and the seed size is small. Rice seeds are easily damaged by friction in the seed metering device. The pneumatic rice seed metering device sucks seeds using negative pressure. It is easy to absorb impurities into the sucking hole when rice seeds are damaged. After a period of accumulation, the sucking hole will become blocked, and the normal operation of the seed metering device will be affected.

At present, methods for cleaning holes are mainly a seed brush or positive pressure. Zhang et al. ${ }^{[14]}$ designed a pneumatic rice seed metering device, which uses a plurality of groups of seed brushes to clean the sucking holes. However, the seed brush cannot be in direct contact with the centre of the sucking hole, and thus, the expected cleaning cannot be achieved. Liao et al. ${ }^{[15]}$ designed a positive and negative pressure combined type rape seed metering device. This device used positive pressure to clear clogged sucking holes. Rapeseed damage produces oil after a long period of work, and dust easily attaches to the sucking hole. It is impossible to remove the debris in the hole because the positive pressure typically used is too small. Liu et al. ${ }^{[16]}$ used a seed scraping device for cleaning cells of a soybean metering device. This method effectively avoided cell clogging. However, this method is only suitable for larger particle seeds, and seeds are easily damaged when they are scraped. Therefore, this device cannot be applied to a rice seed metering device.

There are some defects in the aforementioned methodologies. When a seed brush is used to clean a hole, it is difficult for the brush to touch the inside of the sucking hole and remove the blockage inside the sucking hole. When positive pressure is used to clean the hole, positive pressure also plays a role in blowing rice seeds away from the sucking holes. The working positive pressure should not be too large, so as not to affect the resultant hill diameter and hill spacing. It is difficult to remove the blockage in the sucking hole.

To solve these problems, an active seed throwing and cleaning unit was designed based on the fact that the magnets of the same pole are mutually exclusive.

\section{Working principles}

\subsection{Working principles of the pneumatic rice seed metering device}

An active seed throwing and cleaning unit was designed based on the fact that magnets of the same pole are mutually exclusive. The device replaced the original positive pressure seeding process, and a magnet in the device was installed at the original positive pressure position (the position of the seed throwing remained no change). According to this idea, an active seed throwing and cleaning unit was mounted on the original pneumatic rice precision seeder ${ }^{[17]}$. The pneumatic rice seed metering device with the active seed throwing and cleaning unit mainly consisted of a seed box, stratified room, sucking chamber shell, seed chamber shell, cleaning device, sucking plate, shaft, active seed throwing and cleaning unit and seed tube. The seed metering device is shown in Figure 1.

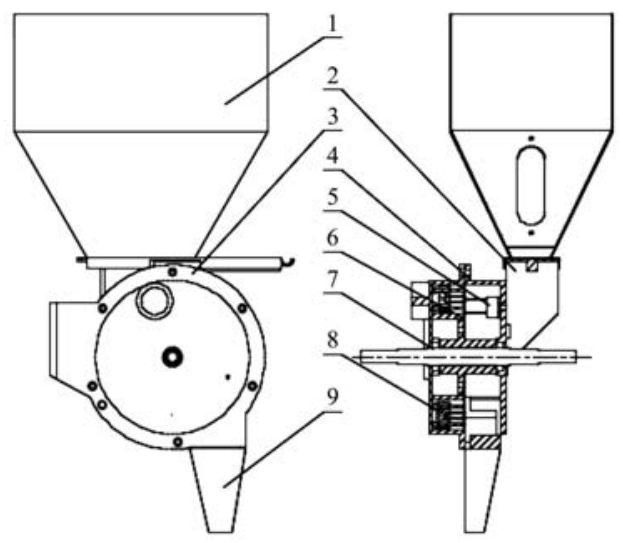

1.Seed box 2. Stratified room 3. Sucking chamber shell 4. Seed chamber shell 5. Cleaning device 6 . Sucking plate 7 . Shaft 8 . Active seed throwing and cleaning unit 9 . Seed tube

Figure 1 Structural diagram of the active seed throwing and

cleaning unit mounted on a rice seeding pneumatic precision metering device

When the seed metering device is operated, the seeds move into the seed filling room of the seed chamber shell through the seed box and stratified room. The seed filling room is filled with seeds, and they accumulate on the surface of the sucking plate. Seeds are sucked into the holes of the sucking plate under the effect of the vacuum of the sucking chamber shell. The seeds rotate with the shaft, and multiple seeds are removed by the seed cleaning device in the clearing area. The seeds leave the seed metering device under the effect of the active seed throwing and cleaning unit and fall into the seed furrow from the seed tube. The seeding process is complete.

\subsection{Working principles of the active seed throwing and cleaning unit}

The active seed throwing and cleaning unit is divided into two parts. One part is a single magnet. It is fixed at the previous positive pressure position inside the sucking chamber shell. The magnet is connected to the sucking chamber shell by a bolt. The other part is installed in the sucking plate of the pneumatic rice seed metering device. The structure of this is shown in Figure 2. The active seed throwing and cleaning unit consists of a shell, linear bearings, a sliding shaft, probes, an end cap, springs and a magnet. Two threaded holes are set on the sucking plate. The distance between the centre of the threaded hole and the centre of the suction plate is $5 \mathrm{~mm}$. Two T-type sliding shafts are designed, and the bottom of the sliding shaft is process threads which is $2 \mathrm{~mm}$. The thread thickness is the same as the thickness of the sucking plate, and the sliding shaft is fixed by the thread hole on the sucking plate. The shell is shown in Figure 2. The inner part of the shell has two round holes, and the linear bearings can be arranged inside. A thread hole is set up at the middle part of the shell, and the end cap is fixed with the shell through a threaded hole. At the same time, the end cap is also fixed with linear bearings to prevent the linear bearings from slipping out of the shell during movement. The bottom end of the end cap is set on two round holes, and the probe can be inserted into a round hole. The location of the probes corresponds to the position of the sucking holes. The diameter of the probe is $1.3 \mathrm{~mm}$. The diameter of the probe is slightly smaller than the diameter of the sucking hole, $1.5 \mathrm{~mm}$. The smaller diameter prevents the probe from interfering with the sucking hole of the sucking plate and avoids influencing the normal operation of the probe. The magnet is fixed on the outer side of the end cap by bolts. The two springs 
are arranged on two sliding shafts, and the length of the spring is the same as the distance between the bottom surface of the shell and the surface of the sucking plate. The spring is relaxed and does not produce elasticity in the shell. When the pneumatic rice metering device starts to work, the active seed throwing and cleaning unit rotates synchronously with the sucking plate. The seeds are absorbed in the sucking hole of the sucking plate by the negative pressure. When the sucking plate is rotated to the seed throwing area, the magnet of the seed throwing area meets the magnet on the active seed throwing and cleaning unit. Due to the principle of same pole mutual repulsion, the fixed magnet will drive the active seed throwing and cleaning unit to the outer movement. The probes also move outward and pass through the sucking hole of the sucking plate. The impurities in the sucking hole and the seeds are pushed away from the sucking plate to complete the seed throwing and cleaning process. In the process, because the repulsion force of the magnet is greater than the spring force of the spring, the spring is compressed in this movement. The device continues to rotate with the sucking plate. After the device leaves the seed throwing area, the magnet repulsion force disappears, and the device is pushed back to its previous position by the elasticity of the spring. At the same time, the probes also leave the sucking holes. When two magnets just meet, the two magnet surfaces are not completely face-to-face which produces small repulsion. Two optical axes are installed and fixed in the active seed throwing and cleaning unit, and the freedom of lateral movement is limited. There is no unilateral movement in this device. To avoid affecting the subsequent sucking seeds of the sucking holes, the process is repeatedly cycled to complete the normal work of the pneumatic rice seed metering device. The sucking chamber shell is made of aluminum in this study. The shell and other parts of the active seed throwing and cleaning unit are made of copper and aluminum. The above materials will not affect the magnet.

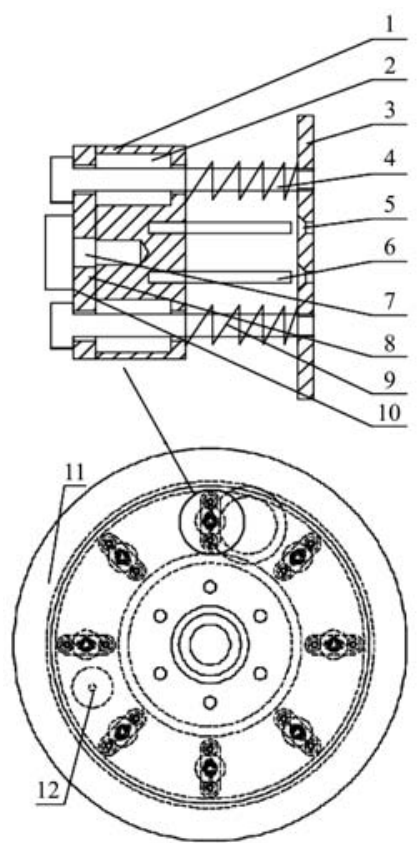

1. Shell 2. Linear bearings 3. Sucking plate 4. Sliding shaft 5. Sucking hole 6. Probes 7. Thread hole 8. End cap 9. Springs 10. Magnet 11. Sucking shell 12 . Magnet of throwing area

Figure 2 Active seed throwing and cleaning unit

\subsection{Theoretical analysis}

The simplified device is shown in Figure 2. A force analysis was carried out on the device. As shown in Figure 3, when the active seed throwing and cleaning unit is rotated to the corresponding throwing area (namely, the fixed magnet position), the magnet on the device will experience the repulsive force $F_{C}$ from the fixed magnet. Because the shell is fixed with the magnet on the device, the whole shell also experiences a repulsive force. At the same time, because the two sliding shafts are sheathed with spring, when the shell is pushed outside by the repulsion of the magnet, the springs will be compressed to produce an elastic $F_{N}$, which prevents the shell from moving outward. Because the relative positions of the two magnets are relatively close, the magnet repulsion between the two magnets is larger, which pushes the whole shell outward. At the same time, the spring will produce resistance. As the outward movement distance increases, the mutual repulsion between the magnets will decrease, while the compressed size of the spring will increase, i.e., the spring will increase the elasticity of the shell. When the repulsion force and the elastic force reach a state of mutual equilibrium, the movement towards the outside will cease. With the rotating sucking plate, the device will leave the throwing area (leave from the fixed position of the magnet). The repulsive force will disappear. The shell is only subjected to the spring force, and it will move to the other side and recover to its previous position. At this time, the spring will recover its original length without producing elastic force. Because a linear bearing is used to slide on the sliding shaft, the friction force caused by sliding is negligible. Because the same two springs are used, the elastic force is basically the same.

According to Figure 3, a force balance equation is as follows:

$$
F_{C}=2 F_{N}
$$

According to theoretical mechanics and mechanics of materials $^{[18]}$, the elastic $F_{N}$ of the spring can be calculated by a formula as follows:

$$
\left\{\begin{array}{l}
F_{N}=K X \\
K=\frac{G d^{4}}{8 D_{m} N_{C}} \\
D_{m}=D_{0}-d \\
N_{C}=N-2
\end{array}\right.
$$

where, $K$ is the stiffness coefficient, $\mathrm{kgf} / \mathrm{mm} ; X$ is the amount of compression, $\mathrm{mm} ; G$ is the rigidity modulus of the material, $\mathrm{kgf} / \mathrm{mm} ; D_{m}$ is the middle diameter of the spring, $\mathrm{mm} ; D_{0}$ is the outside diameter of the spring, $\mathrm{mm}$; $d$ is the wire diameter of the spring, $\mathrm{mm} ; N$ is the total number of cycles of the spring; $N_{C}$ is the number of effective cycles of the spring.

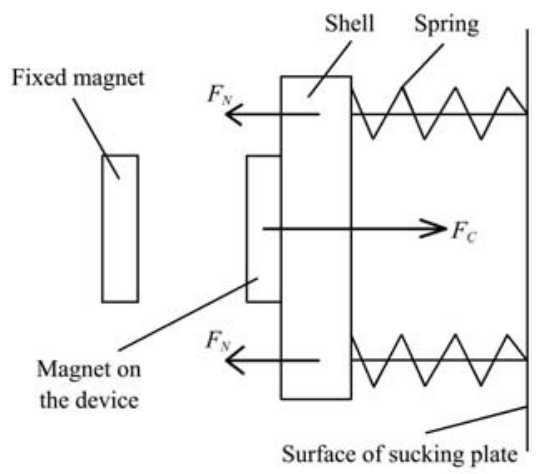

Figure 3 Force analysis diagram

The location of the probe shows that the bottom of the probe is $1 \mathrm{~mm}$ away from the sucking plate, and the thickness of the sucking plate is $2 \mathrm{~mm}$. The seeds are adsorbed on the other side of the sucking plate by the negative pressure adsorption. The 
distance of the probe moving outside should be more than $3 \mathrm{~mm}$ so that the probes can be in contact with the seeds. The plane for sucking seeds is taken as the base plane. To test if the probe length has any impact on the performance of the seed metering device, the lengths of the probes extending out of the base plane are $2 \mathrm{~mm}$ and $4 \mathrm{~mm}$. The spring material is steel wire $(\mathrm{G}=$ $8000 \mathrm{kgf} / \mathrm{mm}^{2}$ ), the wire diameter of the spring is $0.4 \mathrm{~mm}$, the outer diameter is $5 \mathrm{~mm}$, and the total coil number is 7 . According to the theoretical calculation, when the length of the probe extending out of the base plane is $2 \mathrm{~mm}$ (the probe moves $5 \mathrm{~mm}$ ), the spring is compressed $5 \mathrm{~mm}$, and the repulsion force of the magnet is $F_{C}=5.15 \mathrm{~N}$. When the length of the probe extending out of the base plane is $4 \mathrm{~mm}$, the repulsion force of the magnet is $F_{C}=7.22 \mathrm{~N}$. The parameters of the magnet can be calculated according to the length of the probe by using the aforementioned formula. According to the calculated magnetic repulsion, the appropriate magnet is selected to install. The repulsive force required by the magnet cannot be achieved precisely. Therefore, the length of the probe extending out of the base plane is a slight deviation from the theoretical calculation, but it does not affect the normal test.

\section{Materials and methods}

\subsection{Experiment materials}

To verify the effect of the active seed throwing and cleaning unit, a seeding performance test was carried out in the laboratory. The super hybrid rice Y-2 You 900 was selected as the test object. The average size of the seed was $8.90 \mathrm{~mm} \times 2.20 \mathrm{~mm} \times 1.84 \mathrm{~mm}$ (length $\times$ width $\times$ thickness), and the weight of 1000 grains was $23.8 \mathrm{~g}$. The seeds were washed by water to remove impurities and blighted grain. The dry seeds were soaked in clear water for $24 \mathrm{~h}$. Then, they were moistened to bud, filtered out and dried. The average moisture content was $22.5 \%$ (wet basis) before the test.

\subsection{Experiment device}

Experiments were carried out at the JPS-12 Seeding Test Station of the Key Laboratory of Key Technology on Agricultural Machine and Equipment, Ministry of Education, South China Agricultural University. When the seed metering device was tested, the rice seed would drop to the belt of the test station. The belt is covered with a layer of viscous gear oil as it is working. The rice seeds fell and were stuck to the gear oil, so they could not bounce. The hill diameter of rice seeds can be accurately measured. Here is a picture of hills of rice seeds. The effect was shown in Figure 3. To clearly observe the movement of seeds in the seed metering device and the effect of the active seed throwing and cleaning unit, a photosensitive resin was selected as the material of the seed chamber shell. A 3D printer (OBJET350CONNEX3) was used to print the seed chamber shell to facilitate observation and shooting at a later stage. Because the rotational speed of the seed metering device was high, the human eye cannot accurately distinguish the seeds on the sucking plate when the seed metering device was working. Thus, high-speed photography was used to shoot and analyse the throwing area and to record working conditions of the active seed throwing and cleaning unit. A Photron FASTCAM Viewer high-speed camera was used in this study, with the highest number of frames reaching 200000 fps. Because the rotational speed of the seed metering device was only approximately $30 \mathrm{r} / \mathrm{min}$, the shooting number of frames was selected as 200 fps. The resolution was $1024 \times 1024$ pixels. In order to accurately measure the pressure in the seed metering device, the horizontal pressure gauge was used to measure the pressure. Firstly, a threaded hole was arranged on the sucking chamber shell. Secondly, threaded joint was installed in the threaded hole. Waterproof tape was wrapped around threaded joint to prevent pressure leakage from the threaded hole. The rubber hose was used to connect the joint with the horizontal pressure gauge. Pressure value will be measured in this way. The test device is shown in Figure 4.
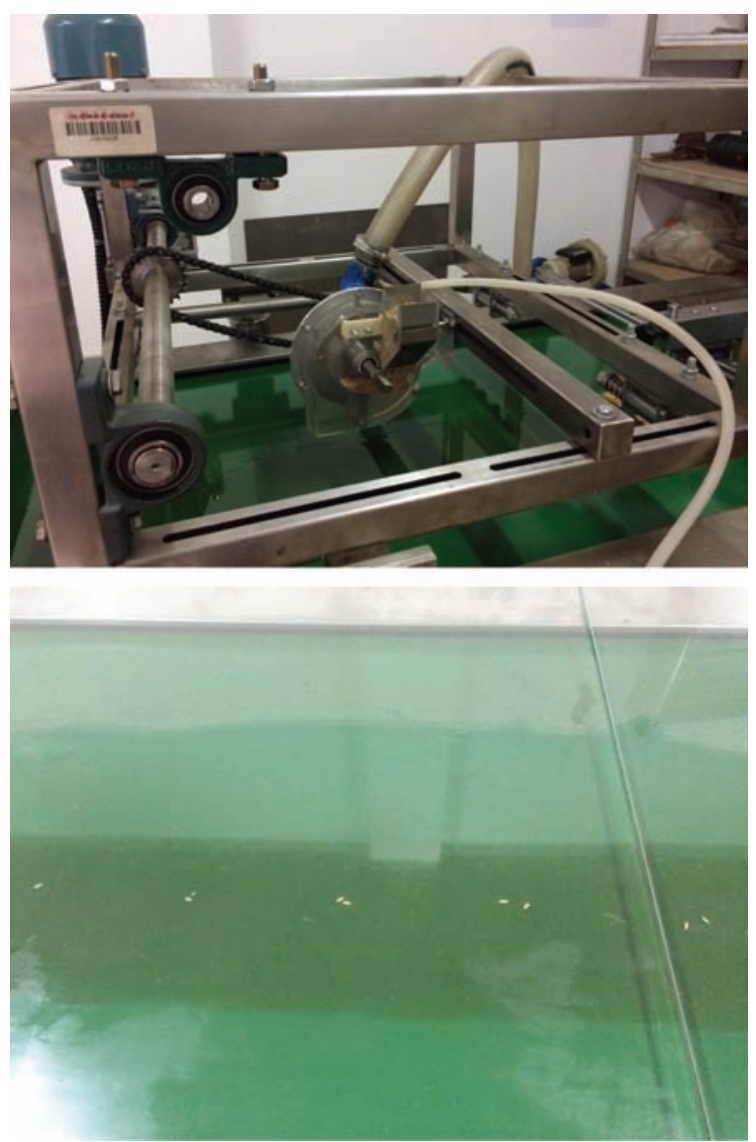

Figure 4 Experimental device

\subsection{Experimental design}

According to the aforementioned theoretical analysis, the performance of the active seed throwing and cleaning unit was mainly affected by negative pressure, the rotational speed of the sucking plate and the size of the probe extending outward. Therefore, the performance of the seed metering device was analysed by a whole factor experiment. The requirement of the forward speed was $0.5-1.0 \mathrm{~m} / \mathrm{s}$ for the field operation. The hill spacing of super hybrid rice was larger than inbred rice, and the average hill spacing was more than $20 \mathrm{~cm}$. The hill spacing was set at $20 \mathrm{~cm}$, and the number of hills on the sucking plate was 8 . According to Equation (3), when the tractor advance speed was $1.0 \mathrm{~m} / \mathrm{s}$, the speed of the corresponding sucking plate was $37.5 \mathrm{r} / \mathrm{min}$. When the tractor advance speed was $0.5 \mathrm{~m} / \mathrm{s}$, the speed of the corresponding sucking plate was $18.75 \mathrm{r} / \mathrm{min}$. Therefore, the rotational speed of the seed metering device was 20-40 r/min.

$$
V_{0}=\operatorname{Snk} / 60
$$

where, $V_{0}$ is the forward speed of tractor, $\mathrm{m} / \mathrm{s} ; S$ is the hill spacing, $\mathrm{m} ; n$ is the rotational speed of sucking plate, $\mathrm{r} / \mathrm{min} ; k$ is the hill number of sucking plate.

The negative pressure was determined by a preliminary test. The experimental factors and levels are shown in Table 1 . The range of negative pressure was determined by reference [5] and pre-experiments. 
Table 1 Experimental factors and levels

\begin{tabular}{cccc}
\hline & \multicolumn{3}{c}{ Factors } \\
\cline { 2 - 4 } Levels & $\begin{array}{c}\text { A (Negative } \\
\text { pressure) } / \mathrm{kPa}\end{array}$ & $\begin{array}{c}\text { B (Rotational speed of } \\
\text { sucking plate) } / \mathrm{r} \cdot \mathrm{min}^{-1}\end{array}$ & $\begin{array}{c}\mathrm{C} \text { (Probe extension } \\
\text { length) } / \mathrm{mm}\end{array}$ \\
\hline 1 & 0.4 & 20 & 2 \\
2 & 0.8 & 30 & 4 \\
3 & 1.2 & 40 & \\
4 & 1.6 & & \\
\hline
\end{tabular}

\subsection{Evaluation and calculation methods}

To record the effect of the active seed throwing and cleaning unit, the shooting results were recorded by high-speed photography. Every 300 hills were taken as a group, and the test was repeated three times. The number of seeds that could not be removed in each group was recorded.

The seeding precision of the improved seed metering device was tested. In reference to the national standard GB-T6973$2005^{[19]}$ regulations, the quantity of total seeds per hole was considered as $X_{k}$ and was successively recorded. Every 250 times was regarded as a group, and three sets of data were obtained. Thus, the average quantity of seeds per hole $(\bar{X})$ could be calculated as follows:

$$
\bar{X}=\frac{1}{750} \sum_{j}^{3}\left(\sum_{k}^{250} X_{k}\right), k=1-250, j=1,2,3
$$

A frequency of $0,1,2,3$, or more seeds per hole from $X_{i}$ was investigated as $x_{t}$. Thus, the sucking probability was $p(i)$. Different seed quantities per hole could be calculated as follows:

$$
p(i)=\frac{\sum_{j=1}^{3} \chi_{i j}}{750}, i=0,1,2,3,4,5,6 \ldots \ldots ; j=1,2,3
$$

To investigate the quality of hill spacing after sowing, the reference standard ${ }^{[5]}$ was used as the criterion. The index of hill diameter less than $5 \mathrm{~cm}$ was used as the qualified index, and the index of hill diameter more than $5 \mathrm{~cm}$ was the unqualified index. The diameter of the hill was recorded. Each 100 hills were taken as a group, and the test was repeated three times. The seeding quantity of each seed-metering device was recorded and analysed using SPSS software ${ }^{[20]}$.

\section{Results and analysis}

\subsection{High-speed photography test results analysis}

The high-speed photography pictures are shown in Figure 5. It can be seen from the diagram that the seeds rotated with the sucking plate to the throwing area. Seeds will be pushed away from the sucking plate by the probes. It will become free falling with initial velocity. The probes remain extended as the active seed throwing and cleaning unit is at the throwing area. The whole process is transient and independent, which will not affect the next group of working. The pictures were counted and analysed. The results showed that the probability of seed throwing and cleaning was $100 \%$ under any test conditions. No seed retention occurred during the test. The test results showed that the active seed throwing and cleaning unit can effectively remove seeds from the sucking holes. The reason was that when the active seed throwing and cleaning unit was working, the device experienced repulsion by the fixed magnet on the shell, and the whole device moved to the side of the sucking plate. The probes passed through the sucking holes of the sucking plate, contacted the seed, and pushed seeds away from the seed metering device. As the probe passed through the sucking plate, the probe blocked most of the airflow in the sucking hole. The airflow was not completely blocked due to the fit gap between the probe and the sucking hole. The blocked air flow reduced the sucking force of the sucking hole to the seeds, preventing the sucking hole from continuing to adsorb seeds. At the same time, the probe contacted with seeds to produce thrust and pushed the seeds out of the sucking plate to complete the whole process of seed throwing and cleaning.

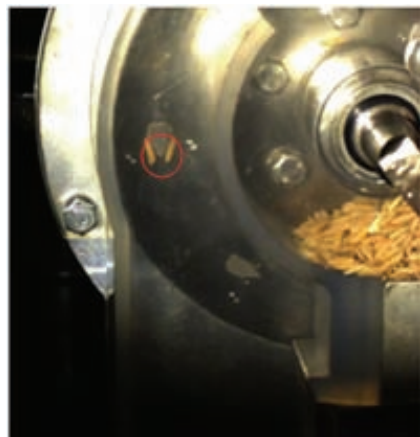

a
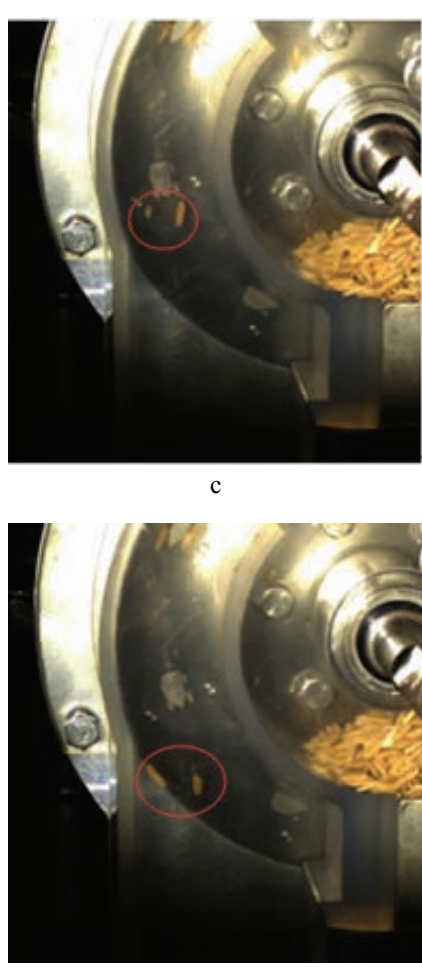

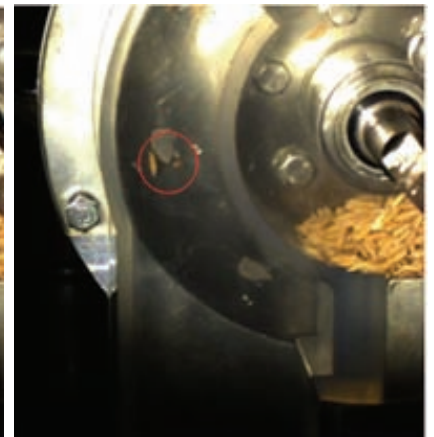

b

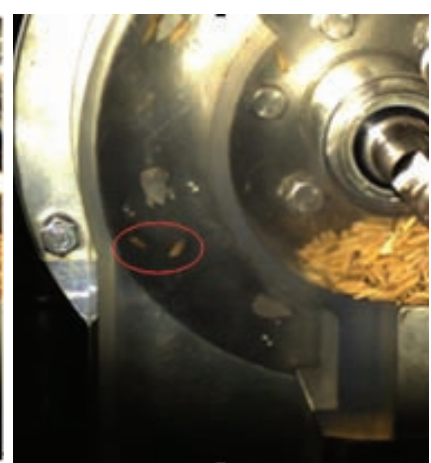

Note: The photo is taken every $0.02 \mathrm{~s}$, and the red circles are seeds. The order in the graph is a-f.

Figure 5 High speed photography

\subsection{Analysis of test results of seeding effect}

The test results for seeding precision are shown in Table 2. The test results show that with an increase in negative pressure, the probability of missed seed and the probability of 1 seed per hill showed a decreasing trend. The probability of missed seed decreased from the highest $12.46 \%$ to the lowest $0 \%$. The probability of one seed per hill decreased from the highest $42.95 \%$ to the lowest $6.23 \%$, and the decreasing trend was obvious. The probability of 3 seeds per hill and the probability of $\geq 4$ seeds per hill showed an increasing trend. The probability of 3 seeds per hill increased from the lowest $12.13 \%$ to the highest $46.23 \%$, and the probability of $\geq 4$ seeds per hill increased from the lowest $0 \%$ to the highest $13.44 \%$. The results showed that an increase in 
negative pressure increased the capacity of sucking seeds, and the phenomenon of multiple sucked seeds was much more common. Therefore, the total sucked seed number increased.

The missed hill was a hill with sucking holes sucking nothing. When the negative pressure was $0.4 \mathrm{kPa}$, which is small, it was not enough to suck more seeds. The probability of two sucking holes without sucking seeds at the same time was significantly increased. When the negative pressure reached $0.8 \mathrm{kPa}$, the negative pressure was doubled as compared with $0.4 \mathrm{kPa}$. The probability of two suction holes without sucking seeds at the same time will be significantly reduced. When the negative pressure was raised to 1.2 or $1.6 \mathrm{kPa}$, the missed hills were further reduced. However, it was almost saturated with sucking seeds. The range of reduction was very small.

When the rotational speed of a seed metering device was increased, the probability of an missed seed was increased under the same condition of negative pressure. The main reason was that the rotational speed of the seed metering device increases, and the rotational speed of the sucking plate was promoted. The time the sucking plate had for sucking seeds was reduced, and the sucking holes did not have enough time to adsorb the seeds. At the same time, the sucked seeds rotated with the sucking plate, and the centrifugal force also increased. This led to an unstable adsorption of seeds that were thrown away from the sucking plate. The probability of missed seed was obviously increased under the influence of these two factors.

The test results from Table 2 showed that when the negative pressure was $0.8 \mathrm{kPa}$, the qualified rate of seeding was the highest, and the stability was approximately $95 \%$. The missed seed rate was less than $4 \%$. At the same time, the rate of 2 seeds per hill was higher, and the seeding was more uniform. The results showed that the optimum seeding negative pressure was $0.8 \mathrm{kPa}$, which could meet the requirement of the field seeding. Meanwhile, the seeding precision of the seed metering device was not influenced by the addition of the active seed throwing and cleaning unit, similar to previous research results.

The influence of the length of the probe on the precision of seeding was also compared. As shown in Table 2, the test results showed that the precision of seeding was not affected under conditions of the same negative pressure and rotational speed of the sucking plate. The main reasons were that the length of the probe was mainly determined by the repulsion force and spring force. Changes in the magnetic repulsion and spring elasticity did not affect the seed filling and sucking in the seed metering device, so the length of the probe does not affect the precision of seeding. However, compared to the hill spacing index, the average qualified rate of the hill spacing was $89.11 \%$ when the length of the probe was $4 \mathrm{~mm}$. When the length of the probe was $2 \mathrm{~mm}$, the average qualified rate of the hill spacing was $96.04 \%$. The qualified rate at a probe length of $2 \mathrm{~mm}$ was higher than the qualified rate at a probe length of $4 \mathrm{~mm}$. The main reason was that when the probe was longer, the seeds were subjected to a larger force of the probe. The larger force of the probe led to a greater horizontal acceleration when seeds left the sucking plate. The seeds were adsorbed and the adsorption gesture was different. When seeds were connected to the active seed throwing and cleaning unit, the action spot of force on the seeds were different. The initial conditions of seed dropping were different under a different action spot of force. The seeds in the same hill had different dropping trajectories. When the seeds of the same hill were subjected to greater force, the dropping trajectories will be changed more substantially, leading to a decrease in the qualified rate of the hill spacing.

Table 2 Test results

unit: \%

\begin{tabular}{|c|c|c|c|c|c|c|c|c|c|c|}
\hline \multirow{2}{*}{ No. } & \multicolumn{3}{|c|}{ Factors and levels } & \multirow{2}{*}{$\begin{array}{l}\text { Missed seeds } \\
\text { per hill }\end{array}$} & \multirow{2}{*}{$\begin{array}{c}1 \text { sucked } \\
\text { seed per hill }\end{array}$} & \multirow{2}{*}{$\begin{array}{c}2 \text { sucked } \\
\text { seeds per hill }\end{array}$} & \multirow{2}{*}{$\begin{array}{c}3 \text { sucked } \\
\text { seeds per hill }\end{array}$} & \multirow{2}{*}{$\begin{array}{l}\geqslant 4 \text { sucked } \\
\text { seeds per hill }\end{array}$} & \multirow{2}{*}{$\begin{array}{c}\text { 1-3 sucked } \\
\text { seeds per hill }\end{array}$} & \multirow{2}{*}{$\begin{array}{l}\text { Qualified rate of } \\
\text { hill space }\end{array}$} \\
\hline & A & B & $\mathrm{C}$ & & & & & & & \\
\hline 1 & 1 & 1 & 1 & 7.86 & 36.07 & 38.03 & 16.07 & 1.97 & 90.17 & 96.04 \\
\hline 2 & 1 & 2 & 1 & 10.82 & 39.34 & 34.10 & 12.79 & 2.95 & 86.23 & 97.03 \\
\hline 3 & 1 & 3 & 1 & 12.46 & 39.34 & 34.43 & 13.11 & 0.66 & 86.88 & 94.06 \\
\hline 4 & 2 & 1 & 1 & 0.98 & 15.74 & 49.51 & 29.84 & 3.93 & 95.09 & 98.02 \\
\hline 5 & 2 & 2 & 1 & 1.64 & 22.30 & 45.57 & 27.87 & 2.62 & 95.74 & 98.02 \\
\hline 6 & 2 & 3 & 1 & 2.95 & 29.84 & 46.56 & 17.70 & 2.95 & 94.1 & 96.04 \\
\hline 7 & 3 & 1 & 1 & 0.66 & 11.48 & 36.07 & 40.33 & 11.46 & 87.88 & 98.02 \\
\hline 8 & 3 & 2 & 1 & 0.33 & 15.08 & 38.69 & 37.05 & 8.85 & 90.82 & 95.05 \\
\hline 9 & 3 & 3 & 1 & 1.31 & 15.41 & 45.57 & 29.18 & 8.53 & 90.16 & 96.04 \\
\hline 10 & 4 & 1 & 1 & 0.66 & 6.23 & 34.75 & 46.23 & 12.13 & 87.21 & 93.07 \\
\hline 12 & 4 & 3 & 1 & 0 & 6.89 & 37.05 & 44.92 & 11.14 & 88.86 & 94.06 \\
\hline 13 & 1 & 1 & 2 & 5.25 & 37.05 & 41.64 & 15.08 & 0.98 & 93.77 & 91.09 \\
\hline 14 & 1 & 2 & 2 & 10.49 & 40.98 & 35.08 & 13.11 & 0.34 & 89.17 & 90.10 \\
\hline 15 & 1 & 3 & 2 & 14.43 & 42.95 & 30.49 & 12.13 & 0 & 85.57 & 89.11 \\
\hline 16 & 2 & 1 & 2 & 2.30 & 19.67 & 46.23 & 28.52 & 3.28 & 94.42 & 92.08 \\
\hline 17 & 2 & 2 & 2 & 3.93 & 22.95 & 46.23 & 24.92 & 1.97 & 94.1 & 88.12 \\
\hline 18 & 2 & 3 & 2 & 3.61 & 31.8 & 44.26 & 19.02 & 1.31 & 95.08 & 85.15 \\
\hline 19 & 3 & 1 & 2 & 1.31 & 12.79 & 36.07 & 38.69 & 11.14 & 87.55 & 90.10 \\
\hline 20 & 3 & 2 & 2 & 1.97 & 16.72 & 42.95 & 28.52 & 9.84 & 88.19 & 85.15 \\
\hline 21 & 3 & 3 & 2 & 2.62 & 15.41 & 42.95 & 27.87 & 11.15 & 86.23 & 89.11 \\
\hline 22 & 4 & 1 & 2 & 0.33 & 6.89 & 35.08 & 45.90 & 11.80 & 87.87 & 88.12 \\
\hline 23 & 4 & 2 & 2 & 0 & 7.87 & 35.41 & 45.25 & 11.47 & 88.53 & 92.08 \\
\hline
\end{tabular}


The results of the tests were analysed using variance analysis. The variance analysis is shown in Table 3 . Table 3 shows that negative pressure had a significant effect on the probability of 1 seed per hill, the probability of 2 seeds per hill, the probability of 3 seeds per hill, the probability of $\geq 4$ seeds per hill and the probability of (1-3) seeds per hill. The rotational speed of the sucking plate had a significant effect on the probability of 1 seed per hill and the probability of 3 seeds per hill. The length of the probe of the active seed throwing and cleaning unit hada significant effect on the qualified rate of the hill spacing. According to the variance results, negative pressure was the main factor affecting seeding precision, but it had no influence on the qualified rate of the hill spacing. The rotation speed of the sucking plate had influence on seeding precision, but it did not affect the qualified rate of the hill spacing. The active seed throwing and cleaning unit had no influence on seeding precision, but it had an influence on the qualified rate of the hill spacing.

Table 3 Analysis of variance

\begin{tabular}{|c|c|c|c|c|c|c|c|c|c|c|c|c|}
\hline \multirow{2}{*}{ Analysis } & \multicolumn{3}{|c|}{ Missed seeds per hill } & \multicolumn{3}{|c|}{1 sucked seed per hill } & \multicolumn{3}{|c|}{2 sucked seeds per hill } & \multicolumn{3}{|c|}{3 sucked seeds per hill } \\
\hline & A & $\mathrm{B}$ & $\mathrm{C}$ & A & $\mathrm{B}$ & $\mathrm{C}$ & A & $\mathrm{B}$ & $\mathrm{C}$ & A & $\mathrm{B}$ & $\mathrm{C}$ \\
\hline SS & 0.036 & 0.002 & 0.000 & 0.345 & 0.011 & 0.001 & 0.047 & 0.000 & 0.000 & 0.319 & 0.018 & 0.001 \\
\hline df & 3 & 2 & 1 & 3 & 2 & 1 & 3 & 2 & 1 & 3 & 2 & 1 \\
\hline MS & 0.012 & 0.001 & 0.000 & 0.115 & 0.006 & 0.001 & 0.016 & 0.000 & 0.000 & 0.106 & 0.009 & 0.001 \\
\hline $\mathrm{F}$ & 49.337 & 4.362 & 0.598 & 163.898 & 8.185 & 1.235 & 15.798 & 0.108 & 0.016 & 149.417 & 12.378 & 1.702 \\
\hline Sig & 0.000 & 0.030 & 0.450 & 0.000 & 0.003 & 0.282 & 0.000 & 0.899 & 0.900 & 0.000 & 0.000 & 0.209 \\
\hline significance & $* *$ & $*$ & & $* *$ & $* *$ & & $* *$ & & & $* *$ & $* *$ & \\
\hline \multirow{2}{*}{ Analysis } & \multicolumn{3}{|c|}{$\geq 4$ sucked seeds per hill\% } & \multicolumn{3}{|c|}{ 1-3 sucked seeds per hill\% } & \multicolumn{3}{|c|}{ Qualified rate of hill space } & & & \\
\hline & A & $\mathrm{B}$ & $\mathrm{C}$ & A & $\mathrm{B}$ & $\mathrm{C}$ & A & $\mathrm{B}$ & $\mathrm{C}$ & & & \\
\hline SS & 0.051 & 0.000 & 0.000 & 0.019 & 0.000 & 0.000 & 0.000 & 0.001 & 0.029 & & & \\
\hline df & 3 & 2 & 1 & 3 & 2 & 1 & 3 & 2 & 1 & & & \\
\hline $\mathrm{F}$ & 160.297 & 2.322 & 0.066 & 17.889 & 1.113 & 0.253 & 0.203 & 1.487 & 67.238 & & & \\
\hline Sig & 0.000 & 0.128 & 0.801 & 0.000 & 0.351 & 0.621 & 0.893 & 0.254 & 0.000 & & & \\
\hline significance & $* *$ & & & $* *$ & & & & & $* *$ & & & \\
\hline
\end{tabular}

Note: $* *$ is significant at $p<0.01 ; *$ is significant at $p<0.05$.

\section{Discussion}

The results of high-speed photography showed that the qualified rate of seed throwing and cleaning were up to $100 \%$. This showed that mutual repulsion between the two magnets could drive the device to achieve the desired effect. However, with an increase in the rotational speed of the sucking plate, the contact time between the two magnets were shortened. When the magnet on the active seed throwing and cleaning unit was pulled out, the moving time to the side of the sucking plate was reduced. This decrease in time leads to a decrease in the movement displacement. The length of the probe was reduced, which adversely affected the throwing and seed cleaning. However, the rotational speed currently used for the seed metering device was approximately $30 \mathrm{r} / \mathrm{min}$, and the corresponding forward speed of the tractor was approximately $0.8 \mathrm{~m} / \mathrm{s}$. This was slow, so the interaction time of the two magnets was sufficient. It did not affect the active seed throwing and cleaning unit. The seeds were pushed away from the sucking holes by the thrust of the probe of the active seed throwing and cleaning unit. As previously mentioned, the probe could not completely cover the sucking hole, so there was still some air flowing through the sucking hole. When the negative pressure increased, the air flow between the probe and the sucking hole also increased. This led to an increase in the sucking force of the gap. When the suction force was sufficient, the probe would not be able to clean the seeds on the sucking hole. Therefore, the seed metering device should not have too much negative pressure. Through the tests previously discussed, it can be found that the optimum negative pressure was $0.8 \mathrm{kPa}$, and the effect of the seed throwing and cleaning was good, meeting the requirements of field application.

Due to the expansion of the size of the probe of an active seed throwing and cleaning unit, the distance between the end of the probe and the surface of the sucking plate was minimal. As air accompanies fluid, it caused some losses when the air flows into a narrow space, hindering the flow. It also impedes the fluid flow. To improve upon this situation, this study processed chamfering for the sucking hole of the sucking plate, which increased the local space of the probe and the sucking hole and reduced the loss of air pressure. It could be seen from the test results that the air flow produced by the gap between the probe and the sucking hole has no influence on the seeding precision. However, the loss of pressure should be further studied and analysed.

The distance between the two sucking holes of the sucking plate was minimal, and the number of the sucking seeds was small. Compared to the seed metering device with multiple seeds, it has a better hill forming property. When the length of the probe was small, the qualified rate of the hill spacing was higher, but the length of the probe could not be too small. When the length of the probe was too short, the adsorbed seeds could not be thoroughly thrown and cleared. When the length of the probe was $2 \mathrm{~mm}$, the hill forming property was good, similar to that of previous researches. The results showed that the active seed throwing and cleaning did not affect the hill forming property.

\section{Conclusions}

In this study, the seed throwing and cleaning part of a pneumatic rice metering device was optimized, and an active seed throwing and cleaning unit was designed. The working principle of the device was analysed, and the mechanical model between the 
repulsion force of the magnet and the spring force of the spring was established.

The super hybrid rice Y-2 You 900 with $22.5 \%$ moisture content (wet basis) was used as the test object, and the effect of the active seed throwing and cleaning unit was studied. The test results showed that the seed metering device could work normally, and the qualified rate of throwing and cleaning was $100 \%$ under any test conditions. The results also showed that the optimal negative pressure was $0.8 \mathrm{kPa}$. The probability of $1-3$ seeds per hill for the seed metering device was approximately $95 \%$ under the optimal negative pressure. This result was similar to previous studies. When the length of the probe was $2 \mathrm{~mm}$, the seed throwing ability was better, and the average qualified rate of hill space was $96.04 \%$, which met the requirements for hill forming.

This research showed that the active seed throwing and cleaning unit could effectively avoid the sucking hole clogging caused by the long-time operation of a rice pneumatic seed metering device, and had no influence on the seeding precision and hill forming properties. The stability of the seed metering device was improved. The research provided a reference for the optimal design of throwing and cleaning structures of the pneumatic rice metering device.

\section{Acknowledgements}

The authors are thankful for funding from National key research program (Project No. 2017YFD07000700, 2017YFD07000704), Commonweal Project (Project No. 201203059), National Natural Science Foundation of China (Project No. 51105147), and Foundation of Guangdong Province of China (Project No. S2011010001948). We would also like to thank the anonymous reviewers for their critical comments and suggestions for improving the manuscript.

\section{[References]}

[1] Farooq M, Siddique K H M, Rehman H, Aziz T, Lee D, Wahid A. Rice direct seeding: Experiences, challenges and opportunities. Soil \& Tillage Research, 2011; 111: 87-98.

[2] Pandey S, Velasco L. Trends in crop establishment methods in Asia and research issues. In: Rice is Life: Scientific Perspectives for the 21st Century, Proceedings of the World Rice Research Conference, 4-7 November 2004, Tsukuba, Japan, pp.178-181.

[3] Chan C C, Nor M A M. Impacts and implications of direct seeding on irrigation requirement and systems management. In: Paper Presented at the Workshop on Water and Direct Seeding for Rice, 14-16 June
1993.Muda Agricultural Development Authority, Ampang Jajar, Alor Setar, Malaysia.

[4] Yang Z Y, Li N, Ma J, Sun Y J, Xu H. High-yielding traits of heavy panicle varieties under triangle planting geometry: A new plant spatial configuration for hybrid rice in China. Field Crops Research, 2014; 168: 135-147. (in Chinese).

[5] Xing H, Zang Y, Wang Z M, Luo X W, Zhang G Z, Cao X M, et al. Design and experiment of filling seed stratified room on rice pneumatic metering device. Transactions of the CSAE, 2015; 31(4): 42-48. (in Chinese).

[6] Yasir S H. Design and test of a pneumatic precision metering device for wheat. Wuhan: Huazhong Agricultural University, 2011. (in Chinese).

[7] Singh R C, Singh G, Saraswat D C. Optimization of design and operational parameters of a pneumatic seed metering device for planting cottonseeds. Biosystems Engineering, 2005; 92(4): 429-438.

[8] Karayel D. Performance of a modified precision vacuum seeder for no-till sowing of maize and soybean. Soil \& Tillage Research, 2009; 104(2): 121-125.

[9] Karayel D, Barut Z B, Ozmerzi A. Mathematical Modelling of Vacuum Pressure on a Precision Seeder. Biosystems Engineering, 2004; 87(4): 437-444.

[10] Karayel D, Wiesehoff M, Zmerz A O, Muller J. Laboratory measurement of seed drill seed spacing and velocity of fall of seeds using high-speed camera system. Computers and Electronics in Agriculture, 2006; 50(2): 89-96.

[11] Ozmerzi A, Karayel D, Topakci M. Effect of Sowing Depth on Precision Seeder Uniformity. Biosystems Engineering, 2002; 82(2): 227-230.

[12] Yazgi A, Degirmencioglu A. Measurement of seed spacing uniformity performance of a precision metering unit as function of the number of holes on vacuum plate. Measurement, 2014; 56(6): 128-135.

[13] Yazgi A, Degirmencioglu A, Onal I, Bayram E. Mathematical modeling and optimization of the performance of a metering unit for precision corn seeding. Journal of Agricultural Machine Science, 2010; 6(2): 107-113.

[14] Zhang G Z, Zang Y, Luo X W, Wang Z M, Zhang Q, Zhang S S. Design and indoor simulated experiment of pneumatic rice seed metering device. Int J Agric \& Biol Eng, 2015; 8(4): 10-18.

[15] Liao Y T, Wang L, Liao Q X. Design and test of an inside-filling pneumatic precision centralized seed-metering device for rapeseed. Int $\mathrm{J}$ Agric \& Biol Eng, 2017; 10(2): 56-62.

[16] Liu H X, Wang F L, Yang G L. New vertical composite plate soybean precision seed-metering device. Transactions of the CSAE, 2007; 23(10): 112-116. (in Chinese).

[17] Xing H, Zang Y, Cao X M, Wang Z M, Luo X W, Zeng S, et al Experiment and analysis of dropping trajectory on rice pneumatic metering device. Transactions of the CSAE, 2015; 31(12): 23-30. (in Chinese)

[18] Beer F P, Johnston E R. Mechanics of materials. Beijing: China Machine Press, 2015. (in Chinese).

[19] GB/T 6973-2005 single (precise) test method. National Standards of the People's Republic of China. (in Chinese).

[20] Li Y Y, Hu C R. Experimental design and data processing. Beijing: Chemical Industry Press, 2008. (in Chinese) 